\title{
INFORMATION SYSTEMS CONTINUANCE: FACULTY PERCEPTIONS OF CANVAS
}

\author{
Leila Halawi, Embry Riddle Aeronautical University, halawil@erau.edu \\ RichardV.McCarthy, Quinnipiac University, richard.mccarthy@quinnipiac.edu \\ James Farah, Jacksonville University, jfarah@ju.edu
}

\begin{abstract}
This research in process proposes a study of the theoretical background, motivation, and methods to examine factors that predict faculty perceived usefulness, ease of use, satisfaction and learning facilitation of the Canvas learning management system. We propose utilizing a model to predict continuance intention of use in an online class using Canvas and describe the methodology that will be used to test this model. The focus of this research is on continuance usage as it is the variable that enhances the teaching and learning experience with factors that are helpful in understanding the phenomenon.
\end{abstract}

Keywords: Information system continuance, e-Learning systems, Canvas

\section{INTRODUCTION}

Research on e-learning systems and the use of different learning management systems has received considerable attention (Lee, Cheung and Chen, 2005; Saade \& Bahli, 2005, Zhang Zhou, Briggs, \& Nunamaker, 2006). For information systems (IS) to be helpful they must be adopted (Davis, 1989) but the longer-term consequences of an information system may be more directly related to its continued use rather than its initial acceptance (Bhattacherjee,2001; Thong, Hong, \& Tam, 2006).

IS continuance is principal to software development companies because clients, market share and revenue hinge on both initial adoption and continued use. The IS community has made enormous effort in examining the user's intention and behaviors in the pre-adoptive stage of systems, but very little knowledge about factors that could influence the user's continuance intention in the post-adoptive stage of e-learning systems in particular has been conducted. The classic information systems continuance model (Bhattacherjee, 2001) may be utilized to predict elearning management system continuance and satisfaction. However, the theory can only partially explain the user's behavioral intention, because it does not consider the influence of the user's particular psychological factors (Bhattacherjee, 2001). An advantage of IS continuance theory is that it offers a model of the psychological motivations of continued use after initial acceptance This research will develop and test a model to predict faculty perceived usefulness, ease of use and satisfaction with Canvas learning management system. The focus of this research is on continuance usage as it is the variable that enhances the teaching and learning experience with factors that are helpful in understanding the phenomenon.

The research will use information systems continuance theory from Bhattacherjee (2001) as a theoretical basis and incorporate added components such as alternate perceptions, personal innovative-ness, and personal influences.

\section{Information Systems Continuance Theory}

Bhattacherjee (2001) grounded the theory of IS Continuance on Oliver's (1980) expectation-confirmation theory from consumer behavior research. The initial model (Figure 1) incorporates three constructs, perceived usefulness, confirmation, and satisfaction to predict IS continuance intention. IS continuance is determined by consumers satisfaction of prior use and satisfaction is determined by two factors, the perceived usefulness and confirmation. Higher levels of confirmation denotes exceeded initial expectation of the user experience while lower levels denotes that the actual use did not meet the expectation. Greater levels of confirmation are thought to have a positive impact on satisfaction of the system. Perceived usefulness fundamentally illustrates expectation perceptions of postconsumption usage and is associated to the TAM factor. Higher levels of perceived usefulness in the system are expected to lead to higher levels of satisfaction. Perceived usefulness is also expected to have a direct effect on IS 
continuance intention. The last relationship in the model is that higher levels of confirmation are expected to have higher levels of perceived usefulness.

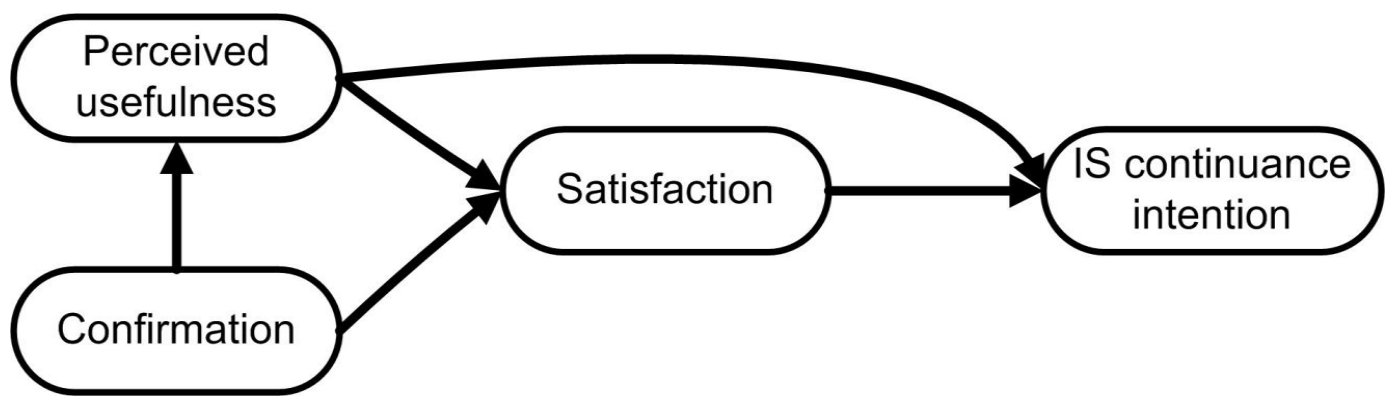

Figure 1. Information System Continuance - Bhattacherjee (2001)

The expectation-confirmation theory (Oliver, 1980) was designed to use both pre-consumption and postconsumption expectations to predict repurchase intentions; conversely, Bhattacherjee's (2001) research examined only the post consumption relationship to predict IS continuance. The results of Bhattacherjee's (2001) suggested that post-consumption behavior is more critical than pre-consumption behavior and Bhattacherjee's later research in 2004 realized that as users developed additional experience with a software product their satisfaction levels regressed toward the mean and had a less predictive power on overall satisfaction.

\section{RESEARCH METHODOLOGY}

This study seeks to answer the following questions:

1- What are the important motivating factors that predict faculty perceived usefulness, ease of use, satisfaction and learning facilitation using Canvas?

2- $\quad$ How do psychosocial factors predict faculty satisfaction with the use of Canvas?

Our proposed research model (Figure 2) will be empirically tested using a survey that will be administered in the fall term of 2018.

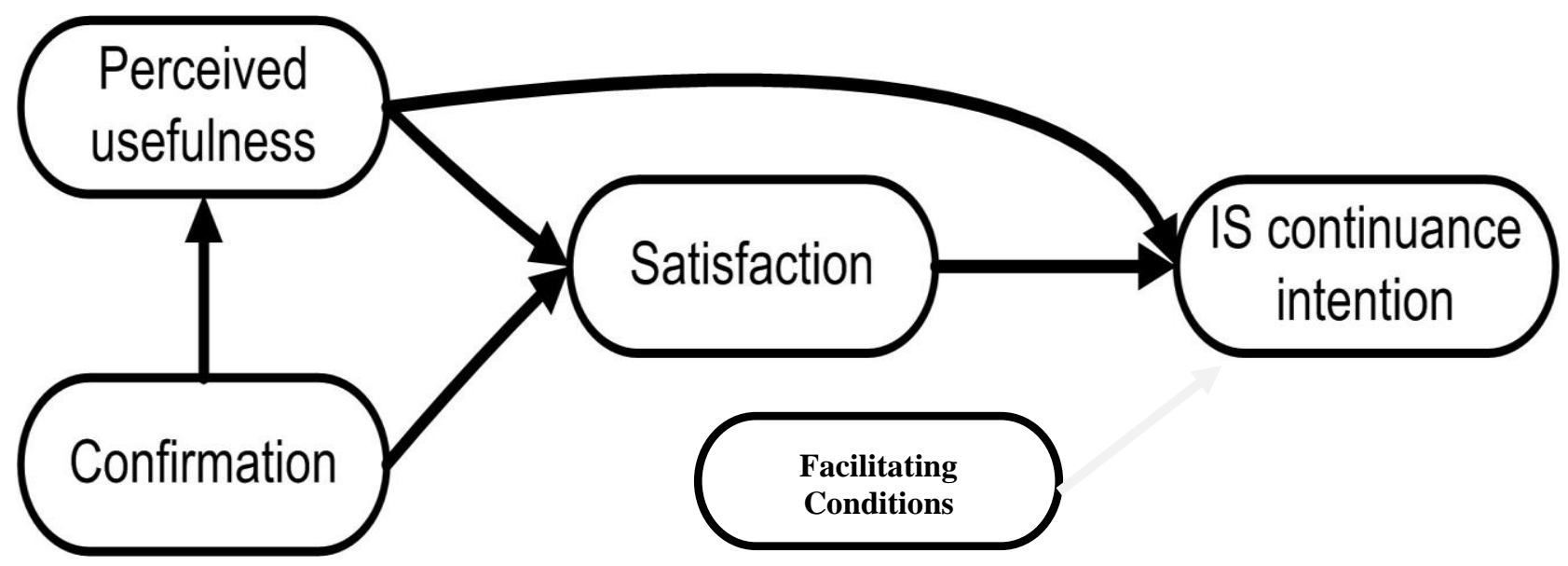

Figure 2. Research model (extended from the expectation confirmation theory)

Extending Bhattacherjee's research (2001), Canvas continuance intention is described as the point to which a user is wishing to maintain Canvas usage. Satisfaction is outlined as the user's gratification response, which is a complete 


\section{Issues in Information Systems}

Volume 19, Issue 4, pp. 171-175, 2018

assessment of a product or service (Kim and Sin, 2011). According to Limayem et al.'s research (2007), perceived usefulness is outlined as the extent to which an individual trusts that he or she may receive values from using Canvas. Confirmation denotes the users' perception of the anticipated values of canvas use and its real performance (Bhattacherjee, 2001). Bhattacherjee (2001) asserted that confirmation positively influences perceived satisfaction since it suggest the fulfilment of the projected benefits of IS use. Facilitating Conditions will examine the degree to which faculty have access to the resources such as dedicated computers, training, whether they have full control over the features, personal innovativeness and perception.

The quantitative research methodology using a non-experimental survey design is the best research approach for explanatory studies. Based on a non-experimental quantitative research approach, this research will use the expectation confirmation model of IS continuance to explain and predict the motivating factors that predict faculty perceived usefulness, ease of use, satisfaction and learning facilitation using Canvas (Bhattacherjee, 2001). In addition, the model will assess and measure faculty satisfaction with the Canvas learning management system.

The purpose of quantitative research can be either descriptive (exploratory) or explanatory. Descriptive research describes a phenomenon and obtains detailed information about its variables. Explanatory research examines and tests the relationships among the variables, seeks answers to research questions, and tests the research hypotheses. Both descriptive and explanatory research are structured and planned using quantitative methods with clearly selected and identified instruments and units of analysis (Singleton \& Straits, 2010).

Surveys are very efficient data-gathering techniques, which can lead to unanticipated findings or new hypotheses. Online surveys require less time to implement and provide more flexibility in the questionnaire design. Online surveys substantially reduce the cost of increasing the sample size, are a less expensive survey method than face-toface, telephone interviews, and mailed questionnaires. Like paper-and-pencil questionnaires, online surveys have a lower response rate than face-to-face and telephone survey methods (Singleton \& Straits, 2010).

This study will involve collecting questionnaires from faculty who use Canvas. An email invitation will be sent to faculty to complete an online questionnaire about their experience this learning management system.

Five constructs will be measured in this study: IS Continuance, Perceived Usefulness, satisfaction and confirmation, in addition to the role of habit. The measures used have been validated in prior research (Davis, 1989; Mathieson, 1991; Steinfield, 1985) and wording will be modified to fit the context of Canvas. In addition, we will test for the perception that the use of Canvas is only utilized because it is mandatory and does not add value.

Structural Equation Modeling (SEM) is a statistical approach to test multivariate models. It allows for testing the relationships between observed (measured indicators) and latent variables (unobserved factors or constructs) i.e. a confirmatory approach. In addition, SEM allows for estimating and testing the significance of the relationships between the constructs of the model and allows the estimating and correcting measurement errors. The SEM technique is a combination of multiple regression, factor analysis, and path analysis (Bagozzi \& Yi, 2012; Hair, Ringle, \& Sarstedt, 2011; Iacobucci, 2009, 2010; Weston \& Gore, 2006).

There are two approaches to SEM, a covariance-based approach (covariance structure analysis) and a partial least square approach (PLS-SEM path modeling). PLS-SEM focuses on the analysis of variance with no assumptions about the data distribution. In addition, it is suitable when little theory is available, accuracy in prediction is important, and the correct model specification is invalid (Hair, Hult, Ringle \& Sarstedt, 2014). The analysis of the data will be performed using partial least squares (PLS)/SEM.

PLS-SEM will allow the testing of the relationships between the observed (measured indicators) and latent variables (unobserved factors or constructs) in the research model. In addition, PLS-SEM will estimate and test the significance of the relationships between the constructs of the model and correcting measurement errors. The PLSSEM analysis in this study will utilize the SmartPLS 3.2 (Hair et al., 2014) software. The PLS-SEM data analysis followed the guidelines provided by Hair, et. al. (2014). 


\section{SUMMARY}

This research provides the theoretical background, motivation and methods to examine the important motivating factors that predict faculty perceived usefulness, ease of use, satisfaction and learning facilitation using Canvas by adapting Bhattacherjee's (2001) information systems (IS) continuance theory to the context of Learning Management Systems. Faculty don't have a choice of which LMS to use, however, the use of an LMS may impact their productivity.

Research into learning management systems fit into the larger domain of information systems research. Information systems continuance in online learning is an important topic because whether users continue to use a given information system has a significant impact on creating sustainable development strategies, and finding valid and reliable business models. This study will draw attention to the substantive differences between acceptance and continuance behaviors.

We intend to extend this research to collect students perceptions using Canvas and subsequently faculty and student perceptions using Blackboard to conduct a comparative study.

\section{REFERENCES}

Bagozzi, R., \& Yi, Y. (2012). Specification, evaluation, and interpretation of structural equation models. Journal of the Academy of Marketing Science, 40(1), 8-34.

Bhattacherjee, A. (2001). Understanding information systems continuance: An expectation-confirmation model. MIS Quarterly, 25(3), 351-370.

Davis, F. D. (1989). Perceived usefulness, perceived ease of use, and user acceptance of information technology. MIS Quarterly, 13(3), 319-340.

Hair, J. F., Hult, G. T. M., Ringle, C. M., \& Sarstedt. (2014). A Primer on Partial Least Squares Structural Equation Modeling (PLS-SEM). Thousand Oaks, CA: Sage Publications, Inc

Hair, J. F., Ringle, C. M., \& Sarstedt, M. (2011). PLS-SEM: Indeed a silver bullet. The Journal of Marketing Theory and Practice, 19(2), 139-152.

Iacobucci, D. (2010). Structural equations modeling: Fit indices, sample size, and advanced topics. Journal of Consumer Psychology, 20(1), 90-98.

Iacobucci, D. (2009). Everything you always wanted to know about SEM (structural equations modeling) but were afraid to ask. Journal of Consumer Psychology, 19(4), 673-680.

Jasperson, J., Carter, P. E. \& Zmud, R.W. (2005), “A comprehensive conceptualization of post-adoptive behaviors associated with information technology enabled work systems", Management Information Systems Quarterly, 29 (3), 525-558.

Kim, K. S. \& Sin, S. C. J. (2011), "Selecting quality sources: bridging the gap between the perception and use of information sources", Journal of Information Science, 37(2), 178-188.

Lee, M. K. O., Cheung, C. M. K., \& Chen, Z. (2005). Acceptance of internet-based learning medium: The role of extrinsic and intrinsic motivation. Information \& Management, 42(8), 1095-1104.

Limayem, M., Hirt, S.G. and Cheung, C.M.K. (2007). How habit limits the predictive power of intention: the case of information systems continuance. Management Information Systems Quarterly, 31(4), 705-738. 


\section{Issues in Information Systems}

Volume 19, Issue 4, pp. 171-175, 2018

Lin, W.S. and Wang, C.H. (2012), "Antecedences to continued intentions of adopting e-learning system in blended learning instruction: a contingency framework based on models of information system success and tasktechnology fit", Computers \& Education, 58(1), 88-99.

Mathieson, K. (1991). Predicting user intentions: Comparing the technology acceptance model with the theory of planned behavior. Information Systems Research, 2(3), 173-191.

Oliver, R. L. (1980). A cognitive model of the antecedents and consequences of satisfaction decisions. Journal of Marketing Research, 17(4), 460469.

Saadé, R., \& Bahli, B. (2005). The impact of cognitive absorption on perceived usefulness and perceived ease of use in on-line learning: An extension of the technology acceptance model. Information \& Management, 42(2), 317-327.

Singleton, R., \& Straits, B. (2010). Approaches to social research (5th ed.). New York, NY: Oxford University Press.

Steinfield, C. W. (1985). Dimensions of electronic mail use in an organizational setting. Proceedings of the Academy of Management, 239-243.

Thong, J. Y., Hong, S.-J., and Tam, K. Y. (2006). The effects of post-adoption beliefs on the expectationconfirmation model for information technology continuance. International Journal of Human-Computer Studies, 64(9), 799810.

Weston, R., \& Gore, P. A. (2006). A brief guide to structural equation modeling. The Counseling Psychologist, 34(5), 719-751.

Zhang, D., Zhou, L., Briggs, R. O., \& Nunamaker, J. F. (2006). Instructional video in e-learning: Assessing the impact of interactive video on learning effectiveness. Information \& Management, 43(1), 15-27. 